\title{
Repeated applications of photodynamic therapy on Candida glabrata biofilms formed in acrylic resin polymerized
}

\author{
Lírian Silva de Figueiredo Freitas ${ }^{1} \cdot$ Rodnei Dennis Rossoni ${ }^{1}$. \\ Antonio Olavo Cardoso Jorge ${ }^{1}$ - Juliana Campos Junqueira ${ }^{1}$
}

Received: 13 August 2016/Accepted: 5 January 2017 / Published online: 14 January 2017

(C) Springer-Verlag London 2017

\begin{abstract}
Previous studies have been suggested that photodynamic therapy (PDT) can be used as an adjuvant treatment for denture stomatitis. In this study, we evaluated the effects of multiple sessions of PDT on Candida glabrata biofilms in specimens of polymerized acrylic resin formed after 5 days. Subsequently, four applications of PDT were performed on biofilms in 24-h intervals (days 6-9). Also, we evaluated two types of PDT, including application of laser and methylene blue or light-emitting diode (LED) and erythrosine. The control groups were treated with physiological solution. The effects of PDT on biofilm were evaluated after the first and fourth application of PDT. The biofilm analysis was performed by counting the colony-forming units. The results showed that between the days 6 and 9, the biofilms not treated by PDT had an increase of 5.53 to $6.05 \mathrm{log}$ $(p=0.0271)$. Regarding the treatments, after one application of PDT, the biofilms decreased from 5.53 to 0.89 $\log$. When it was done four applications, the microbial reduction ranged from $6.05 \mathrm{log}$ to $0.11 \mathrm{log}$. We observed that one application of PDT with laser or LED caused a reduction of 3.36 and 4.64 compared to the control groups, respectively $(p=0.1708)$. When it was done four applications of PDT, the reductions achieved were 1.57
\end{abstract}

Juliana Campos Junqueira

juliana@fosjc.unesp.br

1 Department of Biosciences and Oral Diagnosis, Institute of Science and Technology, UNESP - Univ. Estadual Paulista, Avenida Francisco José Longo 777, São José dos Campos 12245-000, São Paulo, Brazil for laser and 5.94 for LED $(p=0.0001)$. It was concluded that repeated applications of PDT on C. glabrata biofilms showed higher antimicrobial activity compared to single application. PDT mediated by LED and erythrosine was more efficient than the PDT mediated by laser and methylene blue.

Keywords Candida glabrata - Denture stomatitis · Photodynamic therapy $\cdot$ Laser $\cdot$ LED $\cdot$ Photosensitizers

\section{Introduction}

Denture stomatitis (DS) is a common disorder affecting denture wearers and is characterized by inflammation and erythema on the regions of the oral mucosa that are covered by the denture $[1,2]$. This condition is often associates with an infection process with fungus of Candida genus. This disease has higher incidence in the elderly and presents multifactorial etiology, different clinical patterns, and poor symptomatology [3]. The spongy denture tissue surface, full of nutritive substances, is an ideal incubator for Candida species [4, 5]. Candida spp. is a commensal yeast that colonizes the oral cavity of humans, being isolated in approximately $53 \%$ of healthy individuals [6]. In denture wearers, the prevalence of Candida increases until $100 \%$, which can be explained by the fact that dentures decrease the flow of oxygen and saliva to the underlying tissue that favors yeast overgrowth $[5,7]$.

Although $90 \%$ of DS cases are caused by Candida albicans, the non-albicans species, such as Candida glabrata, Candida tropicalis, Candida krusei, Candida parapsilosis, and Candida dubliniensis, can also 
contribute to the pathogenesis of the disease $[2,8,9]$. Recent studies suggested that C. glabrata has been associated with fungemia and its incidence is higher in adults than in children $[10,11]$. This specie represents a growing concern in clinical settings in which it causes mucosal infections and is related to around $15 \%$ of all Candidarelated systemic bloodstream infections [12]. Therefore, the use of dental prosthesis can be a reservoir for C. glabrata and may contribute to the development of a systemic infection in immunocompromised patients.

The conventional treatment for DS is composed of conventional antifungals, such as fluconazole and micafungin. DS caused by $C$. glabrata are more difficult to treat because this specie is intrinsically less active to azoles than $C$. albicans [13]. For example, the epidemiological cutoff value for fluconazole, which indicates the minimum inhibitory concentration value identifying the upper limit of the wild-type population, is $32 \mu \mathrm{g} \mathrm{ml}^{-1}$ in C. glabrata while it is only $0.5 \mu \mathrm{g} \mathrm{ml}^{-1}$ for C. albicans [14]. With the reduction in susceptibility of C. glabrata to antifungal agents and higher incidence of DS in the elderly people, it has resulted in an interest in the development of new therapeutic strategies, such as photodynamic therapy [15].

As an alternative to conventional antifungal therapy, photodynamic therapy (PDT) is a promising modality due to its effectiveness against a broad range of species of microorganisms. In this context, a photosensitizing agent is activated by a light source laser or light-emitting diode at a specific wavelength in the presence of oxygen, resulting in the production of reactive oxygen species (ROS) and free radicals. These ROS disrupt the Candida cytoplasmic membrane and cause an increase in cellular permeability and subsequent damage to intracellular targets $[16,17]$.

The main photosensitizers used in antifungal PDT are phenothiazine (methylene blue), phthalocyanines, and porphyrins associated with lasers and other non-coherent light sources [18-20]. Methylene blue and laser-mediated PDT has been shown to reduce Candida cells in vitro and the epithelial alterations related to oral candidiasis in rats [21-23]. In the PDT against Candida spp. using LEDs, phenothiazines, Photogem photosensitizers, and Xanthene dyes (erythrosine) have been used achieving until $3 \log _{10}$ of reduction. In addition, the erythrosine has attracted interest as a photosensitizer because it is not toxic to the host and is approved for use in dentistry to detect dental biofilms [20, 24, 25].

Since the PDT can be used as an alternative treatment for DS and most of the studies were focused on C. albicans [15, 19-23, 26, 27], the objective of the present study was to evaluate the antimicrobial effects of repeated applications of PDT on C. glabrata biofilms, formed on acrylic resin specimens thermally activated, and to compare the antimicrobial effect of PDT mediated by laser and methylene blue to therapy performed by the LED and erythrosine.

\section{Materials and methods}

\section{Candida strain}

In this study, we used a reference strain of C. glabrata (ATCC 90030). Culture of this strain grown on Sabouraud dextrose agar (Difco, Detroit, Illinois, USA) at $37{ }^{\circ} \mathrm{C}$ for $24 \mathrm{~h}$ was harvested in Sabouraud dextrose broth (Difco, Detroit, Illinois, USA). After an 16-h incubation at $37{ }^{\circ} \mathrm{C}$, the yeasts were centrifuged at $358 \times \mathrm{g}$ for $10 \mathrm{~min}$, washed twice with phosphate-buffered saline (PBS), resuspended in sodium chloride physiological solution, and adjusted to an optical density of 0.284 at $530 \mathrm{~nm}\left(10^{6}\right.$ cells $\left./ \mathrm{ml}\right)$ using a spectrophotometer (B582, Micronal, São Paulo, São Paulo, Brazil).

\section{Photosensitizers}

Methylene blue (Sigma-Aldrich, São Paulo, São Paulo, Brazil) at a concentration of $300 \mu \mathrm{M}$ [22] and erythrosine (Sigma-Aldrich, São Paulo, São Paulo, Brazil) at a concentration of $400 \mu \mathrm{M}$ [20] were used for the sensitization of C. glabrata. The photosensitizers solutions were prepared by dissolving the dye in physiological saline $(0.85 \% \mathrm{NaCl})$ and filtration through a sterile $0.22-\mu \mathrm{m}$ Millipore membrane (Merck-Millipore, Darmstadt, Germany). After filtration, the photosensitizer solution was stored in the dark.

\section{Light sources}

A gallium-aluminum-arsenide (GaAlAs) laser (Easy Laser, Clean Line, Taubaté, São Paulo, Brazil) emitting a continuous light at a wavelength of $660 \mathrm{~nm}$ and a green light-emitting diode (LED) (MMOptics, São Carlos, São Paulo, Brazil) emitting light at a wavelength of $532 \mathrm{~nm}$ were used as the light sources. The laser radiation conditions were an output power of $0.035 \mathrm{~W}$, spot size area of $0.028 \mathrm{~cm}^{2}$, fluence of $26.3 \mathrm{~J} / \mathrm{cm}^{2}$ (energy of $10 \mathrm{~J}$ and time of $285 \mathrm{~s}$ ), and a fluence rate of $92 \mathrm{~mW} / \mathrm{cm}^{2}$. The LED radiation conditions were an output power of $90 \mathrm{~mW}$, spot size area of $0.5 \mathrm{~cm}^{2}$, an energy of $16.2 \mathrm{~J}$, a time of $3 \mathrm{~min}$, a fluence rate of $237 \mathrm{~mW} \mathrm{~cm}$, and a fluence of $42.63 \mathrm{~J} \mathrm{~cm}^{-2}$. The area irradiated in biofilms was $0.94 \mathrm{~cm}^{2}$ at a distance of $0.05 \mathrm{~cm}$ for laser and $0.05 \mathrm{~cm}$ for LED. The optical output of the laser unit was measured before, halfway through, and after the experiment. The laser and LED parameters used in this study were based, respectively, in the studies of Souza et al. [22] and Costa et al. [20].

The temperature at the bottom of the 24-well microtiter plates (Costar Corning, New York, NY, USA) was monitored using an infrared thermometer (MX4, Raytek, Sorocaba, São Paulo, Brazil); no increases in temperature were observed after irradiation with the LED or Laser. 


\section{Confection of an acrylic substrate for biofilm formation}

In order to develop this study, we prepared test specimens measuring $10 \mathrm{~mm}$ in diameter, in acrylic resin polymerized fabricated using polymethylmethacrylate (Vipi Cril plus, VIPI, Pirassununga, São Paulo, Brazil) that is routinely used for the production of dental prosthetics. The specimens were included in metal muffle, pressed in a hydraulic press for $2 \mathrm{~h}$, and then taken to the microwave (ME18S, Electrolux, São Carlos, São Paulo, Brasil) for $15 \mathrm{~min}$ (power $10 \mathrm{~W}$ ) and $5 \mathrm{~min}$ (power $5 \mathrm{~W}$ ). The finishing of the specimens was done with dry sandpaper and polish with pumice using felt disc. Next, the specimens were submerged in distilled water for $48 \mathrm{~h}$ to release the residual monomer. The specimens were sterilized by gamma radiation Cobalt ${ }^{60}$ (20 kGy for $6 \mathrm{~h}$ ) at Empresa Brasileira de Radiações (EMBRARAD, Cotia, São Paulo, Brazil).

\section{In vitro biofilm formation}

The in vitro biofilm formation was performed as described by Vilela et al. [28]. The sterilized acrylic specimens were positioned in the wells of first row of a 24-well culture plate (Costar Corning, New York, USA) containing $2 \mathrm{ml}$ of Brain Heart Infusion broth (BHI, Difco, Detroit, Illinois, USA) with $5 \%$ sucrose. After that, $100 \mu \mathrm{l}$ of standardized microbial suspension of $C$. glabrata was added in the well containing an acrylic specimen immersed in BHI. The plates were incubated at $37^{\circ} \mathrm{C}$ for 5 days. C. glabrata was placed only once, and the BHI broth with $5 \%$ sucrose was changed every $24 \mathrm{~h}$.

After the incubation time, the test samples were transferred to the wells of the next row of the culture plate, with each well containing $2 \mathrm{ml}$ of sterilized saline solution. The plates were shaken for $5 \mathrm{~min}$ in an orbital shaker (Solab, Piracicaba, São Paulo, Brazil) to remove cells loosely attached to the test sample.

\section{In vitro photosensitization}

The formed biofilm were treated with four applications of PDT in $24 \mathrm{~h}$ intervals. For each application of PDT, the specimens were immersed in the photosensitizer and they were shaken for $10 \mathrm{~min}$ in an orbital shaker. Subsequently, the specimens were irradiated with light source in the abovedescribed parameters. The control group was submitted to the same experimental conditions mentioned above; however, the biofilms of control group did not receive photosensitizer and irradiation, and they were treated only with saline.

Each assay was performed in aseptic conditions within a laminar flow chamber and with ambient lights turned off. A black mask with a hole matching the diameter of the wall opening minimized artefacts related to light scattering during the irradiation procedure.
After irradiation, each test sample was placed in a Falcon tube containing $10 \mathrm{ml}$ of sterilized saline and homogenized for $30 \mathrm{~s}$ in a 50-W ultrasonic homogenizer (Sonoplus HD 2200, Bandelin Electronic, Germany) to disaggregate the cells from the biofilm as the experimental groups (Fig. 1).

From the homogenized solution $\left(10^{-1}\right)$, decimal dilutions of the biofilm suspension for each test sample were prepared, and $100 \mu \mathrm{l}$ aliquots of each dilution were spread on plates containing Sabouraud dextrose agar. The plates were incubated at $37^{\circ} \mathrm{C}$ for $48 \mathrm{~h}$. Afterwards, those plates containing from 30 to 300 colonies were used to calculate the colony-forming units (CFU) and converted into logarithm.

\section{Statistical analysis}

The results of the CFU/specimen were statistically analyzed by the program Graph Pad Prism, considering a significance level of $5 \%$.

\section{Results}

The monitoring results of the biofilm growth not treated by PDT on days 6 to 9 demonstrated that there was an increase from 5.53 to $6.05 \mathrm{log}$ of biofilm growth. Despite this difference that was only $0.52 \mathrm{log}$, there was a statistically significant difference between the observation times (Fig. 2).

Regarding to the treatments, the two types of PDT used in this study (association of laser and methylene blue or LED and erythrosine) were able to reduce the $C$. glabrata biofilm with one or four applications of PDT. When a single application of PDT was performed, the quantification of the biofilm was as follows: $5.53 \pm 0.29 \log$ for the control group, $2.17 \pm 1.80 \mathrm{log}$ to PDT with laser, and $0.89 \pm 168 \log$ for PDT with LED. In the treatment of biofilms with four applications of PDT, the microbial reductions observed were more significant, with $6.05 \pm 0.27 \log$ for the control group, $4.48 \pm 0.87 \log$ for PDT with laser, and $0.11 \pm 031 \log$ for PDT with LED (Fig. 3).

Analyzing only the groups treated with PDT, we can observe that the LED protocol with erythrosine was more effective in reducing biofilms than the laser and methylene blue, in both application times (one or four applications). With one application of PDT, the reduction achieved by the laser was $3.36 \log$ and $4.64 \log$ for the LED compared to the control group. With four applications of PDT, laser and LED achieved respectively 1.57 and $5.94 \mathrm{log}$ of microbial reduction compared to the control group (Fig. 4).

\section{Discussion}

In the present study, we evaluated the antimicrobial effects of repeated applications of PDT on C. glabrata biofilms. 
Fig. 1 Study design. PDT, photodynamic therapy; $L E D$, light-emitting diode; $C F U$, colony-forming units

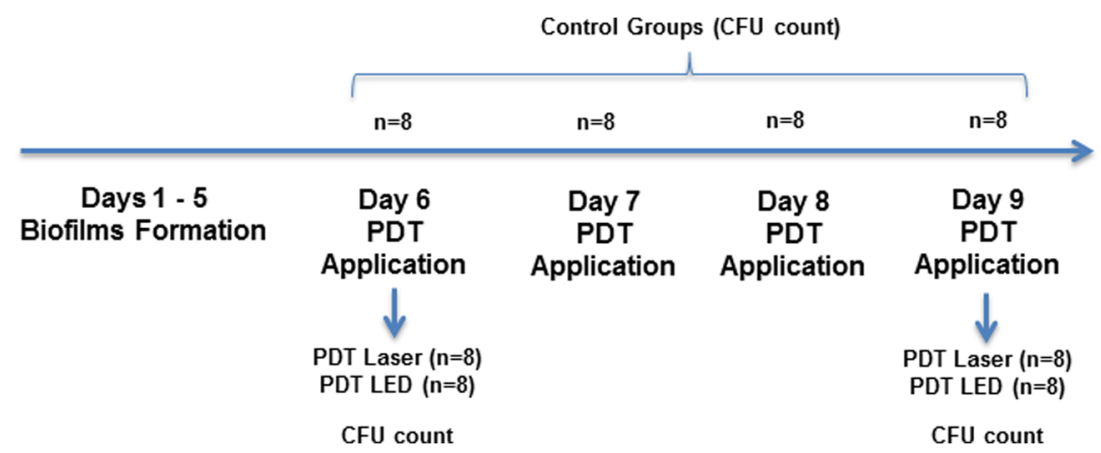

C. glabrata is often the second or third most common cause of candidiasis after $C$. albicans and its infections are difficult to treat due to its resistance to many azole antifungal agents. Consequently, C. glabrata infections have a high mortality rate in immunosuppressed patients [2, 29, 30]. Recently, some members of our group isolated Candida spp. from prosthesisfitting surfaces of 50 individuals wearing removable maxillary prosthesis with lesions of DS and verified that $C$. albicans was the most prevalent specie followed by $C$. glabrata and C. tropicalis. These data indicate the importance in seeking alternative methods as PDT to control the DS caused by nonalbicans Candida species, such as C. glabrata [31].

Kilic et al. [32] assessed the prevalence of DS in different attachment-retained overdenture wearers and its association with particular colonizing Candida species of 37 healthy individuals in Turkey. The authors found that $C$. albicans was the most common species isolated from $81.3 \%$ of patients using bar-retained overdentures and $38.1 \%$ of those using locator-retained overdentures. C glabrata was the second most common species, isolated from $37.5 \%$ of patients using bar-retained overdentures and $23.8 \%$ of those using locatorretained overdentures. The biofilm formation is an important factor to the development of DS in patients who wear dentures and, according Pathak et al. [33], C. glabrata cells in the

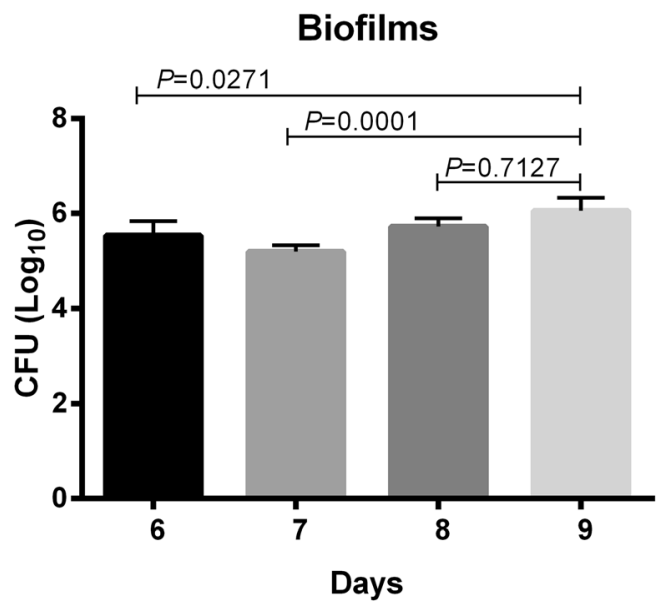

Fig. 2 Mean values and standard deviations of the CFU count $(\log )$ of C. glabrata in the monitoring of biofilms on days 6, 7,8, and 9 (ANOVA and Tukey test, $p<0.05$ ) biofilms are more metabolically active than cells from C. albicans, C. krusei, and C. tropicalis.

Before the study of the effects of PDT on C. glabrata biofilms, initially we did a study to monitor the growth of biofilms not treated by PDT. It was observed that the biofilm had good growth up to day 6 of formation and then it stabilized. This can be explained by the low growth $(0.52 \log )$ of day 6 to day 9 , although there is statistical difference between days. These findings corroborate with Seneviratne et al. [34] who evaluated the growth kinetics of Candida biofilms by counting CFUs after 1.5, 24, 48, and $72 \mathrm{~h}$ of development. The authors found that the candidal biofilm appears to reach its developmental plateau between 24 and $48 \mathrm{~h}\left(0.3-2.2 \times 10^{8}\right.$ cells $\mathrm{ml}^{-1}$ ) with perhaps the highest architectural stability. Then, with increased number of cells, biofilm architecture starts to stabilize by $72 \mathrm{~h}$. In addition, Barros et al. [35] studied the temporal profile of biofilm formation, gene expression, and virulence analysis in $C$. albicans, and they found high expression levels of the transcriptional genes for TEC1, $B C R 1$, and $E F G 1$, which prepare the biofilm for the biomass increase, begin around $12 \mathrm{~h}$ of development and reduce at mature phase (48 h).

Microorganisms in biofilms have a higher resistance to antimicrobial agents and increased protection against the host immune system [15, 23, 33]. According Costa et al. [20], Candida in biofilms have been shown to be less susceptible to photodynamic therapy than fungi in the planktonic phase,

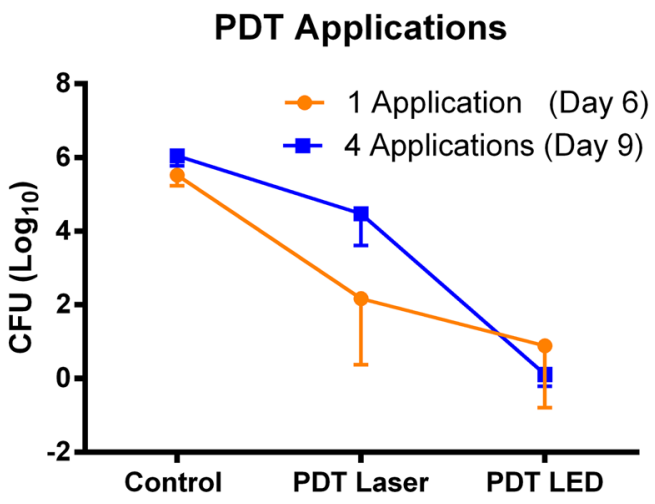

Fig. 3 Mean values and standard deviations of the CFU count $(\log )$ of C. glabrata biofilms in the control group, PDT with laser, and PDT with LED after one or four applications of PDT 


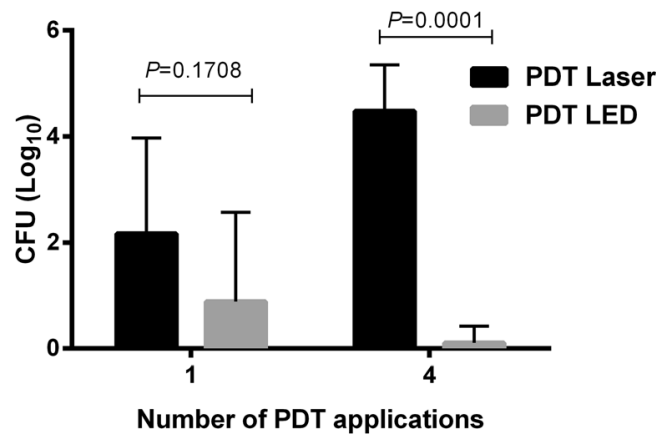

Fig. 4 Mean values and standard deviations of the CFU count $(\log )$ of C. glabrata biofilms of PDT groups of laser and LED after one or four applications (Student's $t$ test, $p<0.05$ )

which could be due the heterogeneity of the biofilm, protection of yeasts by the extracellular matrix material, and the reduced penetration of the photosensitizer in a biofilm. Regarding this effect, Schneider et al. [36] demonstrated that laser irradiation during PDT using phenothiazine chloride as photosensitizer reduced the number of live Streptococcus mutans cells within a layer of only $10 \mu \mathrm{m}$ in an artificial biofilm model evaluated by confocal laser scanning microscope.

With respect to PDT, the two tested modalities (LED or LASER) were able to reduce biofilm of C. glabrata. According Mima et al. [26], PDT is one potential alternative for treating DS, which combines a dye and a light source. These authors evaluated in vitro the effectiveness of one application of PDT for the inactivation of $C$. albicans, C. glabrata, C. tropicalis, C. dubliniensis, and C. krusei on maxillary complete dentures. C. tropicalis was the most species susceptible to PDT and C. dubliniensis and C. glabrata were the least susceptible.

We found promising reductions when a single application of PDT was performed, such as $3.34 \log$ to PDT with laser and $4.64 \log$ for PDT with LED. These reductions of yeasts on biofilms achieved with one session of PDT by the methods employed in this work was greater than the reduction obtained by Junqueira et al. [37] and Quishida et al. [38]. Junqueira et al. [37] evaluated the PDT on seven clinical strains of C. glabrata by association of zinc phthalocyanine and laser on mature biofilms with mean reduction of $0.33 \mathrm{log}$. Quishida et al. [38] studied the effect of PDT with Photodithazine ${ }^{\circledR}$ and LED on biofilm of $C$. glabrata and the highest reduction in the cell viability was equivalent to $1.19 \mathrm{log}$. According to Boyce et al. [39], a minimum of $3 \log$ steps must be achieved to state antimicrobial effect, showing that the protocol of this study can be used as an alternative method to conventional antifungal therapies.

Our reductions with four applications of PDT achieved $4.64 \log$ for laser and $5.94 \log$ with LED compared with the control groups, showing that multiple applications are more efficient than single session therapies. One hypothesis for this fact is that the PDT in multiple sessions weakens the surface of the biofilm becoming it more susceptible to the treatment. To the best of our knowledge, this is the first in vitro study that evaluated multiple applications of PDT mediated by laser and methylene blue on biofilms of C. glabrata. Similarly, Quishida et al. [40] also tested the effectiveness of three applications of PDT mediated by Photodithazine ${ }^{\circledR}$ and LED against biofilms formed by $C$. glabrata on denture base acrylic resin. The $C$. glabrata demonstrated significant differences in relation to the number of applications (one to three PDT sessions) and treatment groups, concluding that three consecutive applications of PDT were more effective for reducing the cell viability and the total biomass of biofilm [40].

In a randomized clinical trial, Mima et al. [41] analyzed the clinical and mycological efficacy of PDT for the treatment of DS and compared with topical nystatin. In the nystatin group, patients received topical treatment with nystatin four times daily for 15 days, and in the PDT group, the denture and palate of patients were sprayed with Photogem ${ }^{\circledR}$, and illuminated by LED three times a week for 15 days. At the end of the treatment (day 15), it was verified that the number of isolates of C. albicans, C. tropicalis, and C. glabrata was reduced by 50 , 90 , and $62.5 \%$, respectively, in the nystatin group and 50 , 45.5, and $71.4 \%$, respectively, in the PDT group compared with the baseline (day 0 ), demonstrating that multiple applications of PDT was so effective as topical nystatin in the treatment of DS.

Recently, Maciel et al. [27] evaluated the PDT combined with low-power laser (LPL) therapy in the treatment of 20 individuals with DS. The PDT group was submitted to one session of methylene blue-mediated PDT plus two sessions of LPL twice a week for 15 days. Forty percent of the patients achieved clinical and microbiological resolution of DS after PDT followed by LPL and 70\% of the patients reported a significant reduction in symptoms (burning sensation and pain associated with DS). The success of these clinical studies using multiple PDT corroborate with our results and demonstrate that PDT in multiple application is more effective compared to PDT with a single application.

Regarding the protocols of PDT employed in this study, the LED and erythrosine was more efficient compared to PDT mediated with laser. In addition, the higher power density of the LED application used in this study compared with laser may have had an advantage on the LED protocol, and consequently achieving better reductions. LEDs are widely used in dental clinics as bleaching tools; moreover, they have shown potent activity in PDT, reduced weight and cost compared to laser, and greater flexibility in treatment irradiation time and easy operation [42, 43]. According to Mima et al. [26], the susceptibility of species of Candida to PDT may vary according to the type, concentration, and time of incubation of photosensitizer and light source used such as laser or LED. The divergences of reductions between our study and results 
reported in the literature might be due to the lack of predefined parameters for the use of PDT, a fact that impairs a reliable comparison between the results obtained in different studies.

Based on the methodology employed in this study and the outcomes obtained, it may be concluded that repeated applications of PDT on biofilms of $C$. glabrata had significant reduction in the biofilm compared to single session. The two protocols of PDT used in this study had antimicrobial effect on the biofilm, although the protocol mediated by LED and erythrosine was more efficient than the laser and methylene blue.

\section{Compliance with ethical standards}

Conflict of interest The authors declare that they have no competing interests.

Role of funding source L.S.F.F. received a doctoral fellowship from Coordenação de Aperfeiçoamento de Pessoal de Nível Superior (CAPES, Brazil).

Ethical approval This article does not contain any studies with human participants or animals performed by any of the authors.

Informed consent Not applicable.

\section{References}

1. Webb BC, Thomas CJ, Willcox MD, Harty DW, Knox KW (1998) Candida-associated denture stomatitis. Aetiology and management: a review. Part 1. Factors influencing distribution of Candida species in the oral cavity. Aust Dent J 43:45-50. doi:10.1111/j.1834-7819.1998.tb00152.x

2. Pereira CA, Domingues N, Araújo MI, Junqueira JC, Back-Brito GN, Jorge AO (2016) Production of virulence factors in Candida strains isolated from patients with denture stomatitis and control individuals. Diagn Microbiol Infect Dis 85:66-72. doi:10.1016/j. diagmicrobio.2016.01.014

3. Iosif L, Preoteasa CT, Murariu-Măgureanu C, Preoteasa E (2016) Clinical study on thermography, as modern investigation method for Candida-associated denture stomatitis. Rom J Morphol Embryol 57:191-195

4. Acosta-Torres LS, Mendieta I, Nuñez-Anita RE, Cajero-Juárez M, Castaño VM (2012) Cytocompatible antifungal acrylic resin containing silver nanoparticles for dentures. Int $\mathrm{J}$ Nanomedicine 7 : 4777-4786. doi:10.2147/IJN.S32391

5. Gleiznys A, Zdanavičienè E, Žilinskas J (2015) Candida albicans importance to denture wearers. A literature review. Stomatologija 17:54-66

6. Coronado-Castellote L, Jiménez-Soriano Y (2013) Clinical and microbiological diagnosis of oral candidiasis. J Clin Exp Dent 5:e279e286. doi:10.4317/jced.51242

7. Sampaio-Maia B, Figueiral MH, Sousa-Rodrigues P, Fernandes MH, Scully C (2012) The effect of denture adhesives on Candida albicans growth in vitro. Gerodontology 29:e348-e356. doi:10.1111/j.1741-2358.2011
8. Silva S, Negri M, Henriques M, Oliveira R, Williams DW, Azeredo J (2012) Candida glabrata, Candida parapsilosis and Candida tropicalis: biology, epidemiology, pathogenicity and antifungal resistance. FEMS Microbiol Rev 36:288-305. doi:10.1111/j.15746976.2011.00278.x

9. Figueiral MH, Azul A, Pinto E, Fonseca PA, Branco FM, Scully C (2007) Denture-related stomatitis: identification of aetiological and predisposing factors - a large cohort. J Oral Rehabil 34:448-455. doi:10.1111/j.1365-2842.2007.01709.x

10. Colombo AL, Guimarães T, Silva LR, de Almeida Monfardini LP, Cunha AK, Rady P, Alves T, Rosas RC (2007) Prospective observational study of candidemia in São Paulo, Brazil: incidence rate, epidemiology, and predictors of mortality. Infect Control Hosp Epidemiol 5:570-576. doi:10.1086/513615

11. Hasan F, Xess I, Wang X, Jain N, Fries BC (2009) Biofilm formation in clinical Candida isolates and its association with virulence. Microbes Infect 11:753-761. doi:10.1016/j.micinf.2009.04.018

12. Rodrigues CF, Silva S, Henriques M (2014) Candida glabrata: a review of its features and resistance. Eur J Clin Microbiol Infect Dis 33:673-688. doi:10.1007/s10096-013-2009-3

13. Vale-Silva LA, Sanglard D (2015) Tipping the balance both ways: drug resistance and virulence in Candida glabrata. FEMS Yeast Res 15:fov025. doi:10.1093/femsyr/fov025

14. Pfaller MA, Andes D, Diekema DJ, Espinel-Ingroff A, Sheehan D, CLSI Subcommittee for Antifungal Susceptibility Testing (2010) Wild-type MIC distributions, epidemiological cutoff values and species-specific clinical breakpoints for fluconazole and Candida: time for harmonization of CLSI and EUCAST broth microdilution methods. Drug Resist Updat 13:180-195. doi:10.1016/j.drup.2010.09.002

15. Costa AC, Rasteiro VM, Pereira CA, Rossoni RD, Junqueira JC, Jorge AO (2012) The effects of rose bengal- and erythrosinemediated photodynamic therapy on Candida albicans. Mycoses 55:56-63. doi:10.1111/j.1439-0507.2011.02042.x

16. Dai T, Huang YY, Hamblin MR (2009) Photodynamic therapy for localized infections - state of the art. Photodiagn Photodyn Ther 6: 170-188. doi:10.1016/j.pdpdt.2009.10.008

17. Freire F, Ferraresi C, Jorge AO, Hamblin MR (2016) Photodynamic therapy of oral Candida infection in a mouse model. J Photochem Photobiol B 159:161-168. doi:10.1016/j.jphotobiol.2016.03.049

18. Mima EG, Pavarina AC, Dovigo LN, Vergani CE, Costa CA, Kurachi C, Bagnato VS (2010) Susceptibility of Candida albicans to photodynamic therapy in a murine model of oral candidosis. Oral Surg Oral Med Oral Pathol Oral Radiol Endod 109:392-401. doi:10.1016/j.tripleo.2009.10.006

19. Dovigo LN, Pavarina AC, Mima EG, Giampaolo ET, Vergani CE, Bagnato VS (2011) Fungicidal effect of photodynamic therapy against fluconazole-resistant Candida albicans and Candida glabrata. Mycoses 54:123-130. doi:10.1111/j.1439-0507.2009.01769.x

20. Costa AC, de Campos Rasteiro VM, Pereira CA, da Silva Hashimoto ES, Beltrame M Jr, Junqueira JC, Jorge AO (2011) Susceptibility of Candida albicans and Candida dubliniensis to erythrosine- and LED-mediated photodynamic therapy. Arch Oral Biol 56:1299-1305. doi:10.1016/j.archoralbio.2011.05.013

21. Junqueira JC, Martins Jda S, Faria RL, Colombo CE, Jorge AO (2009) Photodynamic therapy for the treatment of buccal candidiasis in rats. Lasers Med Sci 24:877-884. doi:10.1007/s10103-0090673-4

22. Souza RC, Junqueira JC, Rossoni RD, Pereira CA, Munin E, Jorge AO (2010) Comparison of the photodynamic fungicidal efficacy of methylene blue, toluidine blue, malachite green and low-power laser irradiation alone against Candida albicans. Lasers Med Sci 5:385-389. doi:10.1007/s10103-009-0706-Z

23. Rossoni RD, Barbosa JO, de Oliveira FE, de Oliveira LD, Jorge AO, Junqueira JC (2014) Biofilms of Candida albicans serotypes A and $\mathrm{B}$ differ in their sensitivity to photodynamic therapy. Lasers Med Sci 29:1679-1684. doi:10.1007/s10103-014-1570-Z 
24. Peloi LS, Soares RR, Biondo CE, Souza VR, Hioka N, Kimura E (2008) Photodynamic effect of light-emitting diode light on cell growth inhibition induced by methylene blue. J Biosci 33:231237. doi:10.1007/s12038-008-0040-9

25. Soares BM, da Silva DL, Sousa GR, Amorim JC, de Resende MA, Pinotti M, Cisalpino OS (2009) In vitro photodynamic inactivation of Candida spp. growth and adhesion to buccal epithelial cells. J Photochem Photobiol B 94:65-70. doi:10.1016/j. jphotobiol.2008.07.013

26. Mima EG, Pavarina AC, Ribeiro DG, Dovigo LN, Vergani CE, Bagnato VS (2011) Effectiveness of photodynamic therapy for the inactivation of Candida spp. on dentures: in vitro study. Photomed Laser Surg 29:827-833. doi:10.1089/pho.2011.3022

27. Maciel CM, Piva MR, Ribeiro MA, de de Santana Santos T, Ribeiro CF, Martins-Filho PR (2016) Methylene blue-mediated photodynamic inactivation followed by low-laser therapy versus miconazole gel in the treatment of denture stomatitis. J Prosthodont 25:2832. doi:10.1111/jopr.12284

28. Vilela SF, Junqueira JC, Barbosa JO, Majewski M, Munin E, Jorge AO (2012) Photodynamic inactivation of Staphylococcus aureus and Escherichia coli biofilms by malachite green and phenothiazine dyes: an in vitro study. Arch Oral Biol 57:704-710. doi:10.1016/j. archoralbio.2011.12.002

29. Fidel PL Jr, Vazquez JA, Sobel JD (1999) Candida glabrata: review of epidemiology, pathogenesis, and clinical disease with comparison to C. albicans. Clin Microbiol Rev 12:80-96

30. Junqueira JC, Vilela SF, Rossoni RD, Barbosa JO, Costa AC, Rasteiro VM, Suleiman JM, Jorge AO (2012) Oral colonization by yeasts in HIV-positive patients in Brazil. Rev Inst Med Trop Sao Paulo 54:17-24. doi:10.1590/S0036-46652012000100004

31. Pereira CA, Toledo BC, Santos CT, Pereira Costa AC, Back-Brito GN, Kaminagakura E, Jorge AO (2013) Opportunistic microorganisms in individuals with lesions of denture stomatitis. Diagn Microbiol Infect Dis 76:419-424. doi:10.1016/j.diagmicrobio.2013.05.001

32. Kilic K, Koc AN, Tekinsen FF, Yildiz P, Kilic D, Zararsiz G, Kilic E (2014) Assessment of Candida species colonization and denturerelated stomatitis in bar- and locator-retained overdentures. J Oral Implantol 40:549-556. doi:10.1563/AAID-JOI-D-12-00048

33. Pathak AK, Sharma S, Shrivastva P (2012) Multi-species biofilm of Candida albicans and non-Candida albicans Candida species on acrylic substrate. J Appl Oral Sci 20:70-75. doi:10.1590/S167877572012000100013

34. Seneviratne CJ, Silva WJ, Jin LJ, Samaranayake YH, Samaranayake LP (2009) Architectural analysis, viability assessment and growth kinetics of Candida albicans and Candida glabrata biofilms. Arch Oral Biol 54:1052-1060. doi:10.1016/j. archoralbio.2009.08.002

35. de Barros PP, Rossoni RD, De Camargo Ribeiro F, Junqueira JC, Jorge AO (2016) Temporal profile of biofilm formation, gene expression and virulence analysis in Candida albicans strains. Mycopathologia. doi:10.1007/s11046-016-0088-2

36. Schneider M, Kirfel G, Berthold M, Frentzen M, Krause F, Braun A (2012) The impact of antimicrobial photodynamic therapy in an artificial biofilm model. Lasers Med Sci 27:615-620. doi:10.1007 /s10103-011-0998-7

37. Junqueira JC, Jorge AO, Barbosa JO, Rossoni RD, Vilela SF, Costa AC, Primo FL, Gonçalves JM, Tedesco AC, Suleiman JM (2012) Photodynamic inactivation of biofilms formed by Candida spp., Trichosporon mucoides, and Kodamaea ohmeri by cationic nanoemulsion of zinc 2,9,16,23-tetrakis(phenylthio)-29H, 31Hphthalocyanine (ZnPc). Lasers Med Sci 27:1205-1212. doi:10.1007/s10103-012-1050-2

38. Quishida CC, Carmello JC, Mima EG, Bagnato VS, Machado AL, Pavarina AC (2015) Susceptibility of multispecies biofilm to photodynamic therapy using Photodithazine ${ }^{\circledR}$. Lasers Med Sci 30: 685-694. doi:10.1007/s10103-013-1397-Z

39. Boyce JM, Pittet D, Healthcare Infection Control Practices Advisory Committee. Society for Healthcare Epidemiology of America. Association for Professionals in Infection Control. Infectious Diseases Society of America. Hand Hygiene Task Force (2002) Guideline for hand hygiene in health-care settings: recommendations of the Healthcare Infection Control Practices Advisory Committee and the HICPAC/SHEA/APIC/IDSA Hand Hygiene Task Force. Infect Control Hosp Epidemiol 23:S3-S40

40. Quishida CC, Mima EG, Dovigo LN, Jorge JH, Bagnato VS, Pavarina AC (2015) Photodynamic inactivation of a multispecies biofilm using Photodithazine(®) and LED light after one and three successive applications. Lasers Med Sci 30:2303-2312. doi:10.1007/s10103-015-1811-9

41. Mima EG, Vergani CE, Machado AL, Massucato EM, Colombo AL, Bagnato VS, Pavarina AC (2012) Comparison of photodynamic therapy versus conventional antifungal therapy for the treatment of denture stomatitis: a randomized clinical trial. Clin Microbiol Infect 18:E380-E388. doi:10.1111/j.1469-0691.2012.03933.x

42. Konopka K, Goslinski T (2007) Photodynamic therapy in dentistry. J Dent Res 86:694-707. doi:10.1177/154405910708600803

43. Pereira CA, Costa AC, Carreira CM, Junqueira JC, Jorge AO (2013) Photodynamic inactivation of Streptococcus mutans and Streptococcus sanguinis biofilms in vitro. Lasers Med Sci 28: 859-864. doi:10.1007/s10103-012-1175-3 